\title{
250STE BESTUURSVERGADERING,
}

GEHOUDEN 15 MAART 1884.

Tegenwoordig de heeren Kern (Voorzitter), J. H. de Groot (Penningmeester), Matthes, Humme, van Deventer, Robidé van der Aa, Niemann, Schlegel, Bool, Wilken en Wijnmalen (Secretaris). Afwezig de heer Weitzel.

$\mathrm{Na}$ opening der Vergadering heet de Voorzitter de nieuw benoemde leden van het Bestuur, de heeren de Groot, Schlegel, van der Aa en Wilken welkom, en beveelt hun de behartiging der belangen van het Instituut aan.

Hierna worden achtereenvolgeus gelezen:

1o. de notulen van het verhandelde in de gewone Bestuursvergadering van den $16^{\text {den }}$ Febr. jl.

20. de notulen van de Algemeene Vergadering, gehouden op Zaterdag, den 23sten Februari jl. en

3o. de notulen van het verhandelde in de buitengewone Bestuursvergadering, na afloop der Algemeene Vergadering, den 23sten Februari jl. gehouden.

De notulen sub. 10. en 30. worden goedgekeurd, terwijl die sub 20. voorloopig worden vastgesteld, ter nadere goedkeuring in de eerstvolgende Algemeene Vergadering.

De Secretaris geeft eene opgave der boekwerken en kaarten, waarmede de bibliotheek opnieuw werd vermeerderd.

Voor kennisgeving aangenomen, onder dankzegging voor de verschillende geschenken.

Ingekomen zijn missives:

10. van Z. Exc. den heer A. W. P. Weitzel, houdende bericht van de aanvaarding zijner herbenoeming tot Vice-president van het Instituut; 
20. van de heeren Prof. Dr. G. Schlegel en G. A. Wilken, beiden te Leiden, houdende bericht van de aanvaarding hunner benoeming tot leden van het Bestuur;

3o. van den Bibliothecaris der Universiteits-Bibliotheek te Christiania, houdende dankbetuiging voor de toegezonden vier feestgaven van het Instituut ter gelegenheid van het zesde Internationale Orientalisten-Congres te Leiden;

4,o. van het Bestuur van de Societatea geografica Romana, ter mededeeling van het programma der algemeene vergadering op 26 en 27 Februari ll.;

$5^{0}$. van het Comité van de Alliance Française, Association nationale pour la propagation de la langue Française dans les colonies et à l'étranger, te Parijs, ten geleide van het programma der in Januari ll. opgerichte vereeniging;

60. van de Asiatic Society of Bengal, te Calcutta, houdende dankbetuiging voor de gelukwenschen haar bij de viering van haar eeuwfeest aangeboden ;

7o. van de heeren A. E. Elias, mr. J. C. van Eijk, H. Prange, H. C. Hartevelt, F. de Stoppelaar, Westerouen van Meeteren, Aug. Mesritz, Jhr. W. H. Teding van Berkhout, A. W. S. Farncombe Sanders, IJ. Feenstra, Prof. dr. E. F. Kruyff, M. J. Waller, Prof. dr. C. H. D. Buys Ballot, mr. W. A. Engelbrecht en C. F. Pabst, allen houdende bericht van de aanvaarding van het lidmaatschap van het Instituut;

8o. van Prof. dr. A. Bastian, te Berlijn, houdende bericht van de aanvaarding zijner benoeming tot buitenlandsch lid van het Instituut.

Alle deze missives worden voor kennisgeving aangenomen.

Aangeteekend wordt het overlijden van de heeren $\mathrm{mr}$. W. A. Henny, te Arnhem, H. F. Morbotter, te 's Gravenhage, en J. W. Middelburg, O. I. ambtenaar met verlof, allen leden van het Instituut.

Ter tafel wordt gebracht een schrijven van den Minister van Koloniën, dd. 6 Maart jl. Lett. A ${ }^{1}$. no. 39, waarbij, in antwoord op het schrijven van het Bestuur van het Instituut van 25 F bruari te voren, no. 1888, wordt medegedeeld dat het rapport van den Commandant van Zijner Majesteits Opnemingsvaartuig "Hydrograaf" omtrent de veranderingen in Straat Soenda na de uitbarsting van Krakatau in zijn geheel is afge- 
drukt in afl. 1. van het $25^{\text {ste }}$ deel van de Mededeelingen betreffende het zeewezen, en dat bij het Departement van Koloniën geene andere gegevens betreffende die vitbarsting voorhanden zijn, welke in aanmerking zouden kunnen komen voor publiceering door het Instituut.

Voor kennisgeving aangenomen.

De Secretaris deelt mede, dat hem vanwege den heer $\mathrm{H}$. E. D. Engelhard, contrôleur le klasse bij het B. B. buiten Java en Madoera, thans met verlof te 's Gravenhage, is ter hand gesteld eene door hem vervaardigde beschrijving van het eiland Saleijer, met kaarten en teekeningen, ter opname in de Bijdragen van het Instituut.

$\mathrm{Na}$ eenige gedachtenwisseling wordt besloten het opstel in handen te stellen van de heeren Matthes en Wilken, met verzoek daaromtrent in de eerstvolgende vergadering rapport uit te brengen, terwijl den Secretaris wordt opgedragen opgaven te verstrekken omtrent de kosten der eventueele uitgave der teekeningen en kaarten.

De Voorzitter deelt mede, dat door hem is ontvangen eene verhandeling over "de Kris, genaamd "Kiahi Pargôlô," eene Indische legende uit de tijden van Modjopahit en Padjadjaran, ten einde daarvan gebruik te maken voor de Bijdragen van het Instituut, voor het geval althans bedoeld opstel daarvoor geschikt wordt geacht. Na onderzoek is het hem echter gebleken, dat het stuk meer op zijne plaats zou zijn in een populair tijdschrift, weswege hij dan ook de opneming daarvan in de Bijdragen ontraadt, met uitnoodiging aan den Secretaris het terug te zenden onder dankbetuiging aan den geëerden inzender voor zijne belangstelling.

Dienovereenkomstig wordt besloten.

Namens het lid J. H. van Balen wordt door de heer Humme verlof gevraagd om voor een door eerstgenoemde uit te geven werk eenige uittreksels te mogen maken van het door het Instituut in zijne feestgave voor het Leidsche OrientalistenCongres opgenomen opstel over de Javaansche sprookjes.

Zonder beraadslaging wordt het gevraagde verlof verleend.

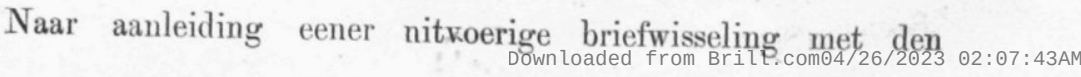


major-general Pearce te Londen vestigt de Voorzitter de aandacht der Vergadering op de wenschelijkheid om vanwege het Instituut eene uitgave te bezorgen van twee Tamil-oorkonden op koperen platen, welke zich bevinden in de Bibliotheek der Universiteit te Leiden.

$\mathrm{Na}$ eenige gedachtenwisseling wordt besloten omtrent de voorgestelde uitgave, die naar het eenparig gevoelen der Vergadering alleszins toejuiching verdient, vooralsnog geene beslissing te nemen, doch haar an te houden tot na den ontvangst eener globale raming van de eventueele kosten, welke de Voorzitter zich bereid verklaart der Vergadering mede te deelen.

Door den Penningmeester wordt de aandacht der Vergadering gevestigd, dat zijns inziens het bedrag der verzekering van de eigendommen van het Instituut op $f 38.000$ te laag geraamd is, waarom hij voorstelt het te stellen op $f 45.000$. Dienovereenkomstig wordt besloten.

Naar aanleiding van de in de Algemeene Vergadering opnieuw behandelde vraag omtrent eene geregelde afschrijving van de waarde van het gebouw stelt de Penningmeester voor tot zulk eene afschrijving, althans voor dit jaar, over te gaan en de waarde van het huis te stellen op $f 25.000$.

$\mathrm{Na}$ eenige beraadslaging vereenigt de Vergadering zich eenparig met dit voorstel.

Niets meer hierna aan de orde zijnde, wordt de Vergadering door den Voorzitter gesloten.

25l STE BESTUURSVERGADERING, GEHOUDEN 19 APRIL 1884.

Tegenwoordig de heeren Kern (Voorzitter), Weitzel (Ondervoorzitter), J. H. de Groot (Penningmeester), van Deventer, Humme, Robidé van der Aa, Matthes, Niemann, Bool, Schlegel, Wilken en Wijnmalen (Secretaris). 
De notulen van het verhandelde in de vorige Vergadering worden gelezen en goedgekeurd.

Door den Secretaris-Bibliothecaris wordt opgave gedaan van de ingekomen boekwerken, waarbij tevens wordt medegedeeld dat ontvangen zijn :

10. eene missive van den Secretaris van Z. H. Prins Roland Bonaparte, ten geleide van een exemplaar van de fotografiën van Kalmukken;

$2^{\circ}$. eene missive van Z. Exc. den Minister van Binnenlandsche Zaken, dd. 8 April 1884, no. 864, Afd. K. en W., ten geleide van acht pakketten met boeken, voor het Instituut bestemd en ontvangen van de Fransche Commissie voor Internationale ruilingen te Parijs:

3o. eene missive van de Directie van het Musée Guimet, te Lyon, dd. 25 Februari n0. 235, houdende bericht dat door tusschenkomst van het Ministerie van Openbaar Onderwijs te Parijs zes pakketten, voor het Instituut bestemd, zijn verzonden, bevattende de door het Musée Guimet uitgegeven werken : welke bezending bereids door den Secretaris in goede orde is ontvangen.

Voor de ontvangen boekwerken zal de dank der Vergadering worden aangeboden.

Nog wordt de ontvangst medegedeeld van:

10. eene missive van de Directie van de Bibliotheek der Universiteit van Noorwegen, te Christiania, houdende dankbetuiging voor de toegezonden laatstelijk uitgegeven Bijdragen, $4 \mathrm{u}^{\mathrm{e}}$ volgreeks, deel 7 ;

20. eene missive van Justus Perthes, te Gotha, houdende kennisgeving van het overlijden van Dr. Erust Behm, redacteur der "Geographische Mitteilungen;"

3o. eene missive van de Secretarissen van de R. Accademia dei Lincei, te Rome, houdende bericht van het overlijden van den president Quintino Sella.

Deze missives worden voor kennisgeving aangenomen.

40. eene missive van den Secretaris van de Accademia dei Lincei, te Rome, houdende verzoek om toezending van het in de bibliotheek dier instelling ontbrekende le stuk van deel VII.

Wordt besloten aan dit verzoek te voldoen. 